\title{
Poverty and Eye Health
}

\author{
Jyoti Jaggernath ${ }^{1,2}{ }^{*}$, Lene Øverland ${ }^{3}$, Prasidh Ramson ${ }^{3}$, Vilas Kovai ${ }^{4}$, Ving Fai Chan ${ }^{5}$, \\ Kovin S. Naidoo ${ }^{1,2,5}$ \\ ${ }^{1}$ African Vision Research Institute, University of KwaZulu-Natal, Durban, South Africa \\ ${ }^{2}$ Vision Cooperative Research Centre, Sydney, Australia \\ ${ }^{3}$ Orbis Africa, Cape Town, South Africa \\ ${ }^{4}$ Brien Holden Vision Institute, Sydney, Australia \\ ${ }^{5}$ Brien Holden Vision Institute, Durban, South Africa \\ Email: ${ }^{*}$ j.jaggernath@brienholdenvision.org.za
}

Received 25 May 2014; revised 9 July 2014; accepted 19 July 2014

Copyright (C) 2014 by authors and Scientific Research Publishing Inc.

This work is licensed under the Creative Commons Attribution International License (CC BY). http://creativecommons.org/licenses/by/4.0/

(c) (i) Open Access

\section{Abstract}

Poverty and eye health, including vision disability from vision impairment and blindness, are believed to be interrelated. The relationship between poverty and eye health can be interpreted as being two-fold, in the sense that poverty may be a cause of poor eye health and poor eye health may lead to or deepen poverty. Evidence shows that the burden of vision impairment is high in poor people and vision impairment and poverty are linked to each other. However the empirical evidence to answer the questions-Does poverty perpetuate poor eye health? How and why? Does poor eye health deepen poverty?-is sparse globally; especially from low and middle income countries (LMICs). This article therefore aims to examine published information and other secondary data sources that provide insight on the relationship between poverty and eye health, including eye disability caused from vision impairment and blindness. The article provides a conceptual understanding of poverty related attributes that contribute to eye disability from vision impairment and blindness, using evidence sourced from poverty and eye health research studies. The article interrogates general theories and beliefs that have been conceptualised in relation to the impact that the vicious cycle of poverty has on eye health and the contribution of poor eye health on an individual's poverty status. The major outcomes of this article include: 1) identifying gaps in linking poverty and eye health, 2) establishing key issues that will assist in the development of a theoretical framework, and 3) preparing more appropriately for further investigation on the association between poverty and eye health.

\section{Keywords}

Poverty, Eye Health, Disability, Barriers, Vision Impairment, Blindness

\footnotetext{
${ }^{*}$ Corresponding author.
} 


\section{Introduction}

Globally, more than three billion people (half of the world's population) live on less than USD \$2 a day [1]. The developing world carries a disproportionate measure of poverty with nine out of ten people living in poverty [2]. The majority of the world's poor are located in Africa (50.9\%), South Asia (40.4\%), East Asia and Pacific (16.8\%), and Latin America and the Caribbean (8.2\%) [2]. Estimates suggest that almost 3.1 billion people (55\% of the total population) live in rural areas and are therefore considered as living in poverty [3]. However, poverty is not confined to only rural areas; urban areas also suffer from concentrated pockets of under-serviced slums [4]. This means that people living in poverty may have little or no access to safe housing, clean water, basic toilet facilities, or health care, which can lead to infectious diseases of all types in rural and urban poor areas. A lack of access to health care services contributes to a wide range of health problems, including poor eye health [5].

Poverty and eye health, including vision disability resulting from vision impairment and blindness are suggested to be directly and often indirectly linked [6]. The majority of preventable eye health problems, such as cataracts, trachoma, conjunctivitis and others, which cause vision impairment and may lead to blindness in developing countries, are closely related to poverty mainly through a lack of sanitation, poor or inadequate water supply, malnutrition and the lack of education [5] —all of which persist in both rural areas and in the slums of some urban areas [7].

Vision impairment remains a serious global health problem in developing countries despite estimates suggesting that $80 \%$ of vision impairment is reversible and curable [8]. Global estimates indicate that there are more than 285 million people who have impaired vision, of which 39 million are blind, and 246 million have low vision [9]. The main causes of vision impairment and blindness worldwide are cataract and uncorrected refractive errors [10]. Glaucoma is included as a third major cause of blindness. The current global distribution of blindness is such that South East Asia leads at 28\%, followed by the Western Pacific at 26\% and Africa at $16.6 \%$ [11]. The lowest blindness prevalence rates are recorded in Eastern Mediterranean (10\%), America (9.6\%), and Europe (9.6\%) [11]. These figures suggest that the prevalence of vision impairment is high in developing countries, with $90 \%$ residing in poverty stricken areas [8] —affecting mostly the poorest of the poor households. The high magnitude of vision impairment in developing countries, especially the rural areas where impoverishment is concentrated, could be due to socio-economic factors that restrict the population from acquiring adequate health services.

The relationship between poverty and eye health can be interpreted as being two-fold, in the sense that poverty may be a cause of poor eye health and poor eye health may lead to or deepen poverty [12]. The dire poverty confronting many developing countries has drastic implications for blindness, vision impairment and eye health services [5]. People from impoverished backgrounds and environments are more likely to experience conditions which contribute and lead to impaired vision [13]. For example, some eye diseases such as trachoma and cataract are perceived as diseases affecting the poor disproportionately, due to their association with poor infrastructure, such as clean water supply, overcrowding and lack of hygiene in poor communities. On the other hand, when individuals go blind or are severely vision impaired, their accessibility to education and other opportunities are affected-mainly due to a loss of income and lack of funds [13]. Severely vision impaired and blind individuals are also limited from accessing and utilising available public services which are often limited in poorer countries [13]. Therefore vision impairment and blindness is both the cause and consequence of poverty. The following section discusses poverty and eye health in the context of disability.

\section{Vision Disability}

Worldwide, more than 10\% of people (approximately 650 million people) have some form of disability that inevitably restricts them from performing certain tasks and functions [14], 70\% of whom live in developing countries, while $82 \%$ live under the poverty line [15]-[17]. Those individuals, who have more recently incurred a disability, are more likely to find themselves under the poverty line in less than a year of the incident [18]. What is even more disconcerting to note is that $64 \%$ of people who are disabled were not trapped in a situation of poverty prior to their disability [12], suggesting that disability may have contributed to income loss, unemployment, low standard of living and high levels of poverty [1] [17] [19]. Thus households affected by disability may be less likely to be alleviated from poverty due to the increased costs and reduced earnings associated with disability [18]. 
Eye health problems and diseases, such as refractive errors, cataracts, glaucoma, diabetic retinopathy and trachoma, amongst others, that cause vision impairment and blindness, affecting millions of people worldwide, are included in the disability spectrum [10]. Thus vision impairment and blindness are significant eye health conditions that add to the causes of disability. At present, nearly $25 \%$ of the population in developing countries are affected by eye diseases or are vision impaired [12].

Poor eye health, causing vision disability, affects people's income and livelihoods, access to basic services such as education and healthcare and also nutrition and development [12]. According to Popikver et al. (2010) vision disability and blindness are most likely to interfere with an individual's life goals such as achieving material wealth, social status, and planning for and raising families [20]. In addition, people with disabilities, such as blindness, may be further impacted upon by a disturbance of mental health, which will affect their life goals and thus perpetuate their poverty [20].

Several dimensions of poverty have a significant impact on the disabled, especially on those individuals who have a vision disability. These dimensions of poverty include employment, material wealth, education, health, poverty alleviation and development assistance, social wellbeing, and public cost [12]. Many of these linked dimensions of poverty would be resolved if the vision of those who are disabled are corrected. For example, if vision was corrected in an individual with vision disability, access to employment would possibly improve, income would improve and the individual would not be dependent on other family members and thus children would be able to attend school regularly instead of taking care of the individual [12]. This argument could be forwarded for each dimension of poverty that impact on eye health (Table 1). Vision problems that remain unresolved will eventually force people to fall deeper into poverty as they will be unable to work and make provisions for their families or conduct daily tasks and thus a heavy reliance will be placed on others for care [20].

\section{Table 1. Multiple dimensions of poverty and eye disability.}

\begin{tabular}{|c|c|}
\hline Dimensions & Impacts \\
\hline Employment & $\begin{array}{l}\text { - Disability results in: loss of employment, reduced productivity, less rewarding jobs, unemployment } \\
\text { especially for women, lower salaries } \\
\text { - In addition disability limits employment for other household members as time is spent on } \\
\text { care-giving } \\
\text { - Restoring sight results in work resumption and enabling caregivers to find employment }\end{array}$ \\
\hline Material wealth & $\begin{array}{l}\text { - Households affected by disability, including vision impairment have: lower average incomes, more } \\
\text { severe income loss, lower savings, higher debt and low asset and land ownership, and lower housing } \\
\text { and amenity standards } \\
\text { - Households also suffer from hunger and food insecurity }\end{array}$ \\
\hline Education & $\begin{array}{l}\text { - Disability impacts on: school participation, children's entrance into schools, literacy levels and } \\
\text { school completion and success } \\
\text { - Girls and women are more affected in terms of school participation and literacy levels } \\
\text { - In addition, disability indirectly impacts on education by disrupting of schooling of children who } \\
\text { stay at home to take care of the disabled }\end{array}$ \\
\hline Health & $\begin{array}{l}\text { - Disabled have: numerous barriers to healthcare, limited access to rehabilitation services, greater risk } \\
\text { of accidents, higher mortality rates, equal or higher risk of HIV exposure and limited HIV/Aids } \\
\text { outreach and treatment services }\end{array}$ \\
\hline $\begin{array}{l}\text { Poverty } \\
\text { alleviation \& development }\end{array}$ & $\begin{array}{l}\text { - Disabled (especially vision impaired) have: limited access to development assistance and poverty } \\
\text { relief }\end{array}$ \\
\hline Social wellbeing & $\begin{array}{l}\text { - Disabled people are socially isolated and have reduced marriage prospects, less partner choices, and } \\
\text { greater abandonment risk } \\
\text { - Disabled people and their families experience low self-esteem and stigma } \\
\text { - Disabled people, especially women experience higher rates of violence \& less assistance with abuse } \\
\text { and have limited decision-making power in and outside household }\end{array}$ \\
\hline Public cost & $\begin{array}{l}\text { - } \quad \text { Direct costs: medical \& related expenses } \\
\text { - } \quad \text { Indirect costs: missed income-earning opportunities \& long term productive potential impact }\end{array}$ \\
\hline
\end{tabular}

Source: Adapted from Gooding et al. (2006: 2-3) [12]. 


\section{Impact of Poor Eye Health}

Poor eye health is likely to have a detrimental effect on mortality [21], quality of life [22]-[24], a person's economic situation [25] and the economic status of regions [26]. Furthermore it causes considerably high economic losses [27], a significant loss of productivity [23] and social exclusion [28]. The onset of disability, from vision impairment, results in lower employment and low productivity [29] [30]. Furthermore, vision impairment impacts negatively on an individual's quality of life and their functionality [31]-[33] and hence has major impact on the global economy [34] [35]. The impact of vision impairment on socio-economic status and quality of life and functionality are discussed further:

\subsection{Socio-Economic}

There is a far greater risk of becoming blind for people in the lower and extreme lower socio-economic status than in people in other socio-economic income categories [30]. For example, in poor countries, disadvantaged communities and especially poor households within these communities in rural and poor regions are more likely to be affected by trachoma [36]. Ho and Schwab (2001) in their comparison of the socio-economic status of countries found an inverse relationship between economic development and blindness [26]. The possibility of blindness was also found to increase with decreasing monthly income according to the findings of the Andhra Pradesh Eye Disease Study [30].

\subsection{Functionality and Quality of Life (QoL)}

Vision loss severely impacts on multiple dimensions of people’s lives. Healthy eyes and good vision play a critical role in the development of an individual and how the person interacts with others in society, therefore, vision loss impacts negatively on an individual's quality of life and their functionality, and has major impacts on the global economy [34] [35]. This is confirmed by numerous studies that show that vision impairment has a major impact on the quality of life of individuals [31]-[33]. QoL is dynamic and subjective to the individual's social, cultural and health perception [33] [37]. For most patients, going blind or losing their vision means adaptation to new conditions and way of life. There are those who consciously adapt, so as to overcome unknown impairments, and learn to function at higher levels than when they first develop the disability [38]. However, for those who find it difficult to accept their condition of functional deficit, their levels of adaptation vary and their ability to cope often influences their functionality and quality of life [38].

Lamouroux et al. (2009), contend that vision impairment/blindness threatens to restrict the individual from being able to conduct daily tasks and maintaining the dignity and respect which is earned by the ability of being independent [32]. Those who are already affected by the disease suffer from other health problems such as depression, distress and sometimes dementia, in cases of older people [37]. Other factors that are affected by vision impairment include physical mobility, functionality, education or academic status and social interaction and overall functionality [33]. These disabling factors of blindness prevent affected individuals from finding employment and securing a good life for themselves, and thus they become more vulnerable to poverty [33].

In addition, individuals who have impaired vision from eye diseases such as trachoma and conditions such as cataracts, often need assistance from their family members and other people to conduct daily tasks as it becomes increasingly difficult for them to move around [39] [40]. Without the ability to move around, including the ability to see where you going, affected individuals are forced to stay at home and furthermore they require the help of an extra able bodied person to assist them. Thus, Lee et al. argue that there is a significant association between vision impairment and a person's functionality [39] [40]. If the person required to care for the blind person is a family member, the affected household is forced to live without the income of the two individuals who have been pre-occupied by the needs of blindness [41]. The lack of income is likely to expose households to risks of becoming poor, and if finance is not acquired soon, the family often sinks deeper into poverty. Children serving the role of care givers may be deprived of an education and subsequently face a greater challenge in escaping poverty as an adult [41].

\section{Barriers Preventing the Poor from Accessing and Utilising Eye Health Services}

The eye health state in developing countries is considerably alarming. The majority of the poor in developing countries are still burdened by treatable and preventable eye diseases, amongst other factors [42]. This suggests 
that poor people are unable to access the health services that they require. An important question to ask then, is "what prevents poor people from accessing and using eye health services"? The evidence suggests that underutilisation of eye health services is aggravated by a wide range of public health issues common to both poverty and blindness such as gender inequalities [43], low socio-economic status [44] [45] [30], low income [46], low employment, illiteracy [47] and cost barriers [48]. In addition gender issues in some cultural contexts become a barrier to the proper correction of vision [5] [49] [50]. Women are often prohibited from accessing eye care services, while it is usually acceptable for men to seek treatment [12]. In some instances cultural beliefs regarding the concept of illness and utilisation of health care results in a sitaution where illness causation is interpreted as social and spiritual disfunction [51] [52]. Supernatural intervention is regarded as the main cause of serious illness in some communities, thus individuals and families seek relief from traditional healers instead of going to the local clinics and health care facilities [52].

\subsection{Barriers to Consider When Developing Eye Health Interventions for the Poor}

Eye health problems and diseases is a pandemic in developing countries due to a lack of resources, inadequate facilities and the lack of knowledge and accessibility to affordable health facilities [5] [13] [53]. Simply addressing health conditions without exploring and dealing with the barriers preventing people from accessing and utilising eye health services effectively hinders societies ability to combat health issues in developing countries [30] [34] [54] [55].

The following barriers need to be understood and considered when developing eye health interventions and implementing eye health strategies for the poor: clinical, knowledge, geographic, and financial barriers. These are discussed below:

\subsubsection{Clinical Barriers}

Clinical barriers that prevent the poor from accessing and utilising eye health services include lack of skilled public sector health practitioners, inadequate equipment and the lack of appropriate facilities to provide quality services [49]. The poor are also prevented from adequate eye health services because the clinical competencies of practitioners are difficult to maintain due to the rapid expansion of knowledge and technology [56]. In addition to these barriers, inadequate application or clinical and translational research results in the delivery of invalidated eye health treatment options. According to Frazier et al. (2009), these barriers result in people, often the poor, not receiving quality care that is adequate and appropriate [56]. Therefore this situation is exacerbated in the developing world—where access to eye health services is already limited, especially for the poor.

\subsubsection{Knowledge Barriers}

Apart from the clinical barriers to accessing eye health services, the lack of eye health knowledge by the poor is another barrier [29]. The majority of people in developing countries, especially those from poor households are illiterate and uneducated when it comes to eye health [42]. Good quality information and advice concerning eye health have not been widely available to the public, especially in developing countries. According to Gilbert (2008), people from poor households lack eye health knowledge, are illiterate and they lack motivation for reasons to correct eye conditions [29]. There are individuals who believe blindness is a natural part of ageing and therefore nothing should be done about it [57]. Gilbert (2008) affirms that for older people in developing countries, going blind is considered inevitable and they see no reason why it should be prevented or treated [29]. The lack of knowledge does not only prevent people from accessing services, but it also perpetuates the conditions which are detrimental to their well-being. As stated by Gooding (2006), households find themselves deeper into poverty after acquiring the disease than before the disease because they lack the knowledge needed to treat their condition [12]. In addition, illiterate people (often those who are poor) are usually left in the dark as some believe that treatment will make their vision worse [51]. In a recent, 2011, study conducted in KwaZulu-Natal by the Brien Holden Vision Institute [57], respondents reported that the fear of poor outcomes from eye correcting techniques prevents them from correcting their vision. Individuals from poor households believed that eye treatment may make their vision worse [57]. In accordance, Gooding (2006), points out that other studies have found that individuals in developing countries are exposed to conditions leading them to contracting eye conditions, and since they lacked knowledge on how to treat them, their lives have changed from good to worse [12]. This situation does not help the poor elevate themselves from poverty, instead being limited from knowledge 
causes them to remain in their poverty stricken situation [51]. Knowledge and education in eye health and the treatment options available as well as the facts and clarification of common misbeliefs are therefore critically important. Gooding (2006) affirms from research conducted that people who have been educated on eye health and the services available are more likely to undertake surgery or any type of vision correction as compared to those who do not receive education and remain illiterate [12]. However, the ability to read and write has been noted as a major challenge for most people in developing countries when being educated on eye health.

\subsubsection{Financial Barriers}

Aside from inadequate or a lack of eye health knowledge, one of the most common barriers to accessing eye health services for the poor is finance [58] [59]. According to Kuper et al. (2010), the majority of individuals who are vision impaired in developing countries fail to meet direct and indirect costs of financing their health care needs [34]. Lack of funds play a huge role in the uptake of health services. Patients experience difficulties paying for treatments, transportation, and often they are unable to take time off from work to visit the health facilities-because they fear losing a day wage [59]. Ninety percent of those who have impaired vision reside in developing countries, most of whom live in conditions of poverty. Their priority is to acquire enough food for nourishment [60] and for most families in poor regions, acquiring food for sustenance is not a guarantee. Intrinsically, it is difficult for them to cater for their basic needs, let alone finance travelling to access health care [58]. People from lower income households are prone to suffer from uncorrected vision impairments [61]. According to He et al. (2007), patients in Nepal indicated that the lack of finances were responsible for their inability to correct their eye conditions, while in rural Nigeria, 61\% of the un-operated patients could not afford eye treatment [49].

Financing eye health services and the uptake of eye correction is usually deciphered by the bread winners in the family or household [62]. In cases where the patient does not have personal savings, the main source of financing their health-related costs are generally supported by other family members. Other common sources of financing health related expenses have been found to be derived from loans or sale of property [59]. Selling property is only an option for the affluent families, since the poor usually do not have property to sell and thus their options to financing their health care needs are very limited.

In the absence of income and financial support from other family members, ill-health persons in developing countries tend to depend on self-made herbal remedies, most of which are self-medication and unsuitable for treating the conditions [51]. Such actions further perpetuate or complicate the condition and by the time they seek out qualified medical help, such as nurses and medical practitioners, their condition has escalated and large sums of funds are required for treatment [51]. In this case, vision impairment and possibly permanent eye disability or blindness pushes the individuals and families deeper into poverty.

The lack of funds has been the most acceptable and convenient explanation for limited use of services available to the public, however, this hypothesis has not been challenged much until the findings by Lewallen (2008), who found that even though some people will claim finances to be the main barrier, when they are interviewed, they give other reasons as well, such as the lack of concern in correcting vision [62]. Poverty is therefore a limiting factor but not the only factor influencing the uptake of services. Other interesting findings include the willingness of the patients to finance their eye health needs [49]. In the study conducted by He et al. (2007), patients with low vision were prepared to pay less than those with good vision, for the correction of their condition [49]. This could be explained by the fact that people with low vision may be restricted further in gaining an income. Further the younger generation was also willing to pay more than the older; this could be explained by the fact that younger people place great value on clear vision and mobility.

\subsubsection{Geographical Barriers}

Accessing affordable services is a difficult task, even for those individuals who are aware of the need to correct their vision [13] [29] [34]. Health care access is not only influenced by socio-economic factors; however the patient's geographical disposition is another determining factor [63]. People in urban areas have multiple health care service providers to choose from in comparison to the rural communities, who often depend on inadequately equipped health facilities [45]. In most instances, people in rural communities travel long distances to the health facilities. Melese et al. (2004) states that apart from financial challenges of paying for treatment, there are other indirect costs associated with travelling to health facilities, which poor people cannot afford [64]. Poor people residing in the remotest of areas have to be content with travelling a full day to the nearest health facility. 
A poor person without sufficient financial resources for travelling will most likely find it difficult to travel to these far off facilities and thus will neglect their eye problem [58]. According to Hou and Chen (2003), blindness, loss of employment, income and disability are associated with neglected eye conditions [58]. Thus when people are forced to neglect their eye problem/s, their quality of life is likely to deteriorate, and may lead them into poverty.

When implementing eye health programmes, it is important to target groups in a population who are most in need. Easy access to eye care should not be determined by socio-economic and geographical factors and even the poorest individuals from the most disadvantaged backgrounds need easy access to health care services [45]. Therefore, services should be implemented in rural areas, since the majority of poor people reside in these areas.

\section{Future Research}

The issues discussed in this article suggest that reducing or alleviating vision impairment among the poor may have a direct impact on poverty alleviation, which is also the first goal of the MDGs. The elimination of vision impairment in those who are poor and the achievement of the goals of MDGs are thus interlinked. In accordance, measures to alleviate vision impairment globally and especially from the developing countries are already in place. These measures include 1) the VISION 2020, the Right to Sight initiative to eliminate avoidable blindness by the year 2020 [65], 2) adopted resolutions and endorsed actions plans at the World Health Assembly (WHA) which have created greater opportunities to merge eye health strategies of national governments within a broader MDG strategy, and 3) an action plan endorsed at the WHA for the Elimination of Avoidable Blindness and Visual Impairment [66].

These measures are aimed at restoring sight and are anticipated to assist in alleviating most of the dimensions related to poverty and disability, however comprehensive quantifiable data is needed to show 1 ) whether poverty perpetuates poor eye health, 2) does poor eye health deepen poverty?, and 3) do eye health interventions assist in alleviating poverty? The following section focuses on the research questions identified in this article. Research questions that need investigation are listed in Table 2.

Table 2. Emerging research themes and questions.

\begin{tabular}{|c|c|}
\hline Theme & Research questions \\
\hline Deprived basic needs & $\begin{array}{l}\text { - What difficulties do people with poor eye health experience when accessing specific needs, such as the } \\
\text { need to go to the latrine or restroom or be able to access safe drinking water, compared to those who do not } \\
\text { have an eye problem or condition? }\end{array}$ \\
\hline $\begin{array}{c}\text { Changes due to } \\
\text { deprived capacities }\end{array}$ & $\begin{array}{l}\text { - What detrimental changes (related to economic deprivation) occurred in households where there is a person } \\
\text { - with impaired vision or is blind? } \\
\text { - } \quad \text { If yes, does it contribute to a loss in family income? } \\
\text { - In such circumstances, what are the detrimental financial and non-financial consequences of such } \\
\text { - households? } \\
\text { - What is the socio-demographic profile of households with persons with an impaired vision or are blind? } \\
\text { impairment due to cataract or refractive errors lead to increased debt and deepen poverty? }\end{array}$ \\
\hline $\begin{array}{c}\text { Social and economic } \\
\text { prejudice }\end{array}$ & $\begin{array}{l}\text { - Does prejudice towards disabled persons due to blindness influence social exclusion and access to social } \\
\text { interaction and financial or non-financial assistance? } \\
\text { - What is the distribution of income and expenditures among the vision impaired and those with good vision } \\
\text { within households? } \\
\text { - Are vision impaired and blind persons deprived of economic resources compared to those who are not } \\
\text { disabled? } \\
\text { Does the discrimination of blind people lead to deprivation of basic needs such as access to a balanced diet } \\
\text { or quality health care? }\end{array}$ \\
\hline $\begin{array}{c}\text { Work related } \\
\text { changes and costs }\end{array}$ & $\begin{array}{l}\text { - What changes are there for people with vision impairment in terms of work productivity, loss of } \\
\text { employment or change in employment role? } \\
\text { - Do these changes impact on household income and expenses? } \\
\text { - What is the economic burden of vision impairment and blindness as a disability? }\end{array}$ \\
\hline
\end{tabular}


The following themes are identified in connection with eye health and poverty—anticipated to assist researchers fill in the gaps with regard to poverty and vision impairment or blindness.

\subsection{Deprived Basic Needs}

An important research question is the quantification of the level of difficulty that people with poor eye health have to access specific needs, such as the need to go to the latrine or restroom or be able to access safe drinking water, compared to those who do not have an eye problem or condition.

\subsection{Changes Due to Deprived Capacities}

While the relationship between poverty and eye health was presented in this review, further research is needed to understand why and how changes in the lives of people with vision impairment or blindness restrict their optimal function.

Information is needed on levels of employment loss or lack of opportunities, external credit and the use of poverty alleviation services. The information should be correlated to the demographic characteristics (such as age, gender, education) of households. This will help inform appropriate efforts in the alleviation of poverty.

\subsection{Social and Economic Prejudice}

There is a need to determine whether prejudice towards disabled members due to blindness has any role in social exclusion and access to social interaction and financial or non-financial assistance. An in-depth understanding of the distribution of income and expenditures among the vision impaired and those with good vision within household is also needed. The usual assumption in some studies related to inequality and poverty and disability is that disabled persons are deprived of economic resources to that of those not disabled [67] [68]. Whether the same is true in the case of households with blind people needs research. Further, whether the discrimination of blind people leads to deprivation of basic needs such as access to a balanced diet or quality health care also requires investigation.

\subsection{Work Related Changes and Costs}

Work and cost issues are closely interlinked and complicated when compounded with disability. However, their relationship with eye health has been limitedly studied. Due to extra costs of disability, households containing persons with impaired vision or blindness are less likely to save, the chance of them becoming vulnerable when external financial shocks occur and the role of money lenders and how is the money channelled should be researched as these may compound the risk of poverty. As work opportunity has an important role in the alleviation of poverty, the changes for people with vision impairment in terms of work productivity (working hours; earning capacity; income), loss of employment or change in employment role, assets and debt, has to be studied as these will impact on earning and costs of households.

Results from comparative studies on the extent that blindness affects the ability of households to meet basic needs, costs of medical care, expenditures, economic satisfaction for the households with disabled members to that of households without disabled persons can also give important insights on the economic burden of vision impairment and blindness as a disability, and additionally help to advocate for blindness prevention interventions.

\section{Conclusions}

The literature reviewed in this article presents theoretical evidence that poverty and poor eye health in developing countries is closely related. The evidence from this review indicates:

- Poor people are subjected to limited access to employment opportunities and basic services such as education, water and sanitation, and health—all of which affect eye health and vision restoration or treatment.

- The state of eye health in developing countries is still alarming despite the various interventions that have been subsidised to address the condition.

- Poor people face significant barriers in accessing eye health services such as poor clinical services, financial, limited eye health knowledge and geographical barriers. 
- Vision impairment and blindness is likely to impact on social and economic opportunities for affected individuals and can contribute to plunging individuals further into poverty. The association between poverty and eye health will impact on the achievement of the MDGs.

- In poverty struck environments, the poor and elderly are the most likely to be vulnerable to eye diseases.

- People experiencing at least one marker of poverty are more likely to develop certain eye diseases, less likely to seek care for those diseases and are more likely to have a poor outcome after treatment.

In consideration to the review findings, it can be assumed that the cycle of poverty starts and will not end unless strong interventions and programmes are implemented. Much realignment in policy needs to occur, particularly at the local community level. The planning of services by authorities needs to be multi-dimensional with all critical sectors being concurrently addressed. Eye health and health in general should be located within the broader efforts in society to improve the socio-economic conditions of communities. Limited gains will be achieved by addressing clinical and service delivery challenges without creating an enabling environment that improves access to food, water, good infrastructure and ultimately jobs. The value of current national eye care plans needs to be reviewed as they are often focused on eye care outcomes and do not sufficiently integrate both financially and managerially with other government departments which are integral to poverty alleviation.

The limited literature available indicates that there is a need to invest considerably in research to quantify the impact of poverty on eye health and vice versa. At best, the current literature serves as a possible indicator of the link between poverty and eye health. These investments will need to be central to government's anti-poverty and eye health strategies. A point in example is the War on Poverty Campaign (WOPC) of the South African government which encompasses efforts to provide services and support for the poorest of the poor families in the country [69]. The first step in this campaign has been a research project that quantifies the key issues.

Finally, in addressing eye health, it is imperative to consider the various inter and intra-regional dimensions of poverty as well as the varying degrees of the burden of poverty that influence vision impairment. Good health is a cornerstone of growth, development and poverty alleviation; and blindness is a major barrier to achieving these development goals in countries with a large population existing under the poverty line. Vision impairment and blindness will continue to be a serious problem in developing countries if appropriate attention is not placed on the development of serious interventions and measures that tackle poverty and provide the necessary services needed by the poor.

Does poverty lead to blindness or vice versa is the question to be answered in further studies. The causal links between disability and poverty also requires further investigation. In addition, more empirical data is required to prove that measures to reduce blindness also alleviate poverty. Hence, while further research studies are essential to determine factors leading to blindness or vision impairment, an equally important strategy to investigate their links to poverty is essential.

\section{Acknowledgements}

The authors would like to thank Orbis Africa, the Brien Holden Vision Institute, the African Vision Research Institute and the South African Governments Department of Social Development for support. We also thank the Vision Cooperative Research Centre (VCRC) for supporting the contribution of the African Vision Research Institute to the Poverty and Eye Health project. Appreciation is expressed to Dr Robert Lindfield for his contribution and support to the Poverty and Eye Health initiative.

\section{References}

[1] Mitra, S., Posarac, A. and Vick, B. (2011) Disability and Poverty in Developing Countries: A Snapshot from the World Health Survey. World Bank Discussion Paper, No. 1109. http://wwwwds.worldbank.org

[2] Santiaguel, M. The Role of Cooperatives in Global Poverty Reduction. http://www.cooperativeunionofcavite.com

[3] International Fund for Agricultural Development (IFAD) (2011) Rural Poverty Report 2011: Overview. www.ifad.org/rpr2011

[4] Grant, U. (2010) Spatial Inequality and Urban Poverty Traps. Overseas Development Institute Working Paper 326. http://www.odi.org.uk/sites/odi.org.uk/files/odi-assets/publications-opinion-files/5502.pdf

[5] Naidoo, K. (2007) Poverty and Blindness in Africa. Clinical and Experimental Optometry, 90, 415-421. http://dx.doi.org/10.1111/j.1444-0938.2007.00197.x

[6] Kuper, H., Polack, S., Eusebio, C., Mathenge, W., Wadud, Z. and Foster, A. (2008) A Case-Control Study to Assess 
the Relationship between Poverty and Visual Impairment from Cataract in Kenya, the Philippines and Bangladesh. Plos Medicine, 5, e244. http://dx.doi.org/10.1371/journal.pmed.0050244

[7] UN-Habitat (2007) Urban Poverty and Slum Dwellers. http://www.unhabitat.org/

[8] World Health Organisation (2011) Prevention of Blindness and Visual Impairment, Priority Eye Diseases. http://www.who.int/blindness/causes/priority/en/index2.html

[9] Pascolini, D. and Mariotti, S.P. (2012) Global Estimates of Visual Impairment: 2010. British Journal of Ophthalmology, 96, 614-618. http://dx.doi.org/10.1136/bjophthalmol-2011-300539

[10] Resnikoff, S., Pascolini, D., Mariotti, S.P. and Pokharel, G.P. (2008) Global Magnitude of Visual Impairment Caused by Uncorrected Refractive Errors in 2004. Bulletin of World Health Organization, 86, 63-70. http://dx.doi.org/10.2471/BLT.07.041210

[11] World Health Organisation (2010) Causes of Blindness and Visual Impairment. Prevention of Blindness and Visual Impairment. http://www.who.int/blindness/causes/en/

[12] Gooding, K. (2006) Poverty and Blindness: A Survey of the Literature. Sightsavers. International Programme Development Unit. http://www.sightsavers.org

[13] Khanna, R., Raman, U. and Rao, G. (2007) Blindness and Poverty in India: The Way forward. Clinical and Experimental Optometry, 90, 406-414. http://dx.doi.org/10.1111/j.1444-0938.2007.00199.x

[14] International Labour Office (2011) Equality at Work: The Continuing Challenge. Report of the Director-General under the Follow-Up to the ILO Declaration on Fundamental Principles and Rights at Work. International Labour Conference 100th Session Report I (B), Geneva.

[15] Christian Blind Mission (2011) Cataract Report Shows Financial Gains for Under-Developed Countries. Media Release. http://www.cbmarchive.org

[16] European Commission (2003) Guidance Note on Disability and Development for EU Delegations and Services. DG Development, Brussels.

[17] Elwan, A. (1999) Poverty and Disability: A Survey of the Literature. Social Protection Unit, Human Development Network, World Bank, Social Protection Discussion Paper No. 9932. www.handicap-international.fr/bibliographie.../HandPovSurvey.pdf

[18] Holden, B.A., Fricke, T.R. and Ho, S.M. (2008) Global Vision Impairment Due to Uncorrected Presbyopia. Archive of Ophthalmology, 126, 1731-1739. http://dx.doi.org/10.1001/archopht.126.12.1731

[19] Javitt, J., Sommer, A. and Venkataswamy, G. (1983) The Economic and Social Impact of Restoring Sight. In: Henkind, P. Ed., ACTA: 24th International Congress of Ophthalmology, Philadelphia, 1308-1312.

[20] Popivker, L., Wang, S.W. and Boerner, K. (2010) Eyes on the Prize: Life Goals in the Context of Visual Disability in Midlife. Clinical Rehabilitation, 24, 1127-1135. http://dx.doi.org/10.1177/0269215510371421

[21] McCarty, C.A., Nanjan, M.B. and Taylor, H.R. (2001) Vision Impairment Predicts 5 Years Mortality. British Journal of Ophthalmology, 85, 322-326. http://dx.doi.org/10.1136/bjo.85.3.322

[22] Polack, S., Kuper, H., Mathenge, W., Fletcher, A. and Foster, A. (2007) Cataract Visual Impairment and Quality of Life in a Kenyan Population. British Journal of Ophthalmology, 91, 927-932. http://dx.doi.org/10.1136/bjo.2006.110973

[23] Polack, S., Kuper, H., Wadud, Z., Fletcher, A. and Foster, A. (2008) Quality of Life and Visual Impairment from Cataract in Satkhara District. Bangladesh. British Journal of Ophthalmology, 92, 1026-1030. http://dx.doi.org/10.1136/bjo.2007.134791

[24] Vu, H.T., Keeffe, J.E., McCarty, C.A. and Taylor, H.R. (2005) Impact of Unilateral and Bilateral Vision Loss on Quality of Life. British Journal of Ophthalmology, 89, 360-363. http://dx.doi.org/10.1136/bjo.2004.047498

[25] Rein, D.B., Zhang, P., Wirth, K.E., Lee, P.P., Hoerger, T.J., McCall, N., Klein, R., Tielsch, J.M., Vijan, S. and Saaddine, J. (2006) The Economic Burden of Major Adult Visual Disorders in the United States. Archive of Ophthalmology, 124, 1754-1760. http://dx.doi.org/10.1001/archopht.124.12.1754

[26] Ho, V.H. and Schwab, I.R. (2001) Social Economic Development in the Prevention of Global Blindness. British Journal of Ophthalmology, 85, 653-657. http://dx.doi.org/10.1136/bjo.85.6.653

[27] Frick, K.D. (2012) What the Comprehensive Economic of Blindness and Visual Impairment Can Help Us to Understand. Indian Journal of Ophthalmology, 60, 406-410. http://dx.doi.org/10.4103/0301-4738.100535

[28] Vale, D. (2004) Unseen: Neglect, Isolation and Household Poverty amongst Older People with Sight Loss. Royal Institute of Blind, London. http://www.rnib.org.uk/livingwithsightloss/Documents/Unseen_Report_PDF.pdf

[29] Gilbert, C.E., Shah, S.P., Jadoon, R.B., Dineen, B., Khan, A.M., Johnson, G.J. and Khan, M.D. (2008) Poverty and Blindness in Pakistan: Results from the Pakistan National Blindness and Visual Impairment Survey. British Medical 
Journal, 336, 29-32. http://dx.doi.org/10.1136/bmj.39395.500046.AE

[30] Dandona, R. and Dandona, L. (2001) Review of Findings of the Andhra Pradesh Eye Disease Study: Policy Implications for Eye-Care Services. Current Ophthalmology, 49, 215-234.

[31] Essue, B.M., Hackett, M.L., Mueller, A., Duc, N.T.H., Phuc, H.T. and Jan, S. (2011) Investigating the Psychological and Economic Impact of Cataract Surgery in Vietnam: The Visionary Observational Study Protocol. BMC Ophthalmology, 11, 25. http://dx.doi.org/10.1186/1471-2415-11-25

[32] Lamoureux, E., Fenwick, E., Moore, K., Klaic, M., Borschmann, K. and Hill, K. (2009) Impact of the Severity of Distance and Near-Vision Impairment on Depression and Vision-Specific Quality of Life in Older People Living in Residential Care. Investigative Ophthalmology and Visual Science, 50, 4103-4109. http://dx.doi.org/10.1167/iovs.08-3294

[33] Payot, A. and Barrington, K.J. (2011) The Quality of Life of Young Children and Infants with Chronic Medical Problems: Review of the Literature. Current Problems in Pediatric and Adolescent Health Care, 41, 91-101. http://dx.doi.org/10.1016/j.cppeds.2010.10.008

[34] Kuper, H., Polack, S., Mathenge, W., Eusebio, C., Wadud, Z., Rashid, M. and Foster, A. (2010) Does Cataract Surgery Alleviate Poverty? Evidence from a Multi-Centre Intervention Study Conducted in Kenya, the Philippines and Bangladesh. PLoS ONE, 5, Article ID: e15431. http://dx.doi.org/10.1371/journal.pone.0015431

[35] Du Toit, R., Palagyi, A., Ramke, J., Brian, G. and Lamoureux, E.L. (2010) The Impact of Reduced Distance and Near Vision on the Quality of Life of Adults in Timor-Leste. Ophthalmology, 117, 2308-2314. http://dx.doi.org/10.1016/j.ophtha.2010.03.041

[36] Frick, K.D. and Foster, A. (2003) The Magnitude and Cost of Global Blindness: An Increasing Problem that Can Be Alleviated. American Journal of Ophthalmology, 135, 471-476. http://dx.doi.org/10.1016/S0002-9394(02)02110-4

[37] Bekibele, C. and Gureje, O. (2008) Impact of Self-Reported Visual Impairment on Quality of Life in the Ibadan Study of Aging. British Journal of Ophthalmology, 92, 612-615. http://dx.doi.org/10.1136/bjo.2007.124859

[38] Richman, J., Lorenzana, L.L., Lankaranian, D., Dugar, J., Mayer, J., Wizov, S. and Spaeth, G. (2010) Relationships in Glaucoma Patients between Standard Vision Tests, Quality of Life and Ability to Perform Daily Activities. Ophthalmic Epidemiology, 17, 144-151. http://dx.doi.org/10.3109/09286581003734878

[39] Lee, P.P., Smith, J.P. and Kington, R. (1999) The Association between Self-Rated Vision and Hearing and Functional Status in Middle Age. Ophthalmology, 106, 401-405. http://dx.doi.org/10.1016/S0161-6420(99)90082-9

[40] Lee, P.P., Smith, J.P. and Kington, R. (1999) The Relationship of Self-Rated Vision and Hearing to Functional Status and Well-Being among Seniors 70 Years and Older. American Journal of Ophthalmology, 127, 447-452. http://dx.doi.org/10.1016/S0002-9394(98)00418-8

[41] Keeffe, J.E., Chou, S.L. and Lamoureux, E.L. (2009) The Cost of Care for People with Impaired Vision in Australia. JAMA Ophthalmology, 127, 1377-1381. http://dx.doi.org/10.1001/archophthalmol.2009.242

[42] Majeed, M., Williams, C., Northstone, K. and Ben-Shlomo, Y. (2008) Are There Inequities in the Utilisation of Childhood Eye-Care Services in Relation to Socio-Economic Status? Evidence from the ALSPAC Cohort. British Journal of Ophthalmology, 92, 965-969. http://dx.doi.org/10.1136/bjo.2007.134841

[43] Nirmalan, P.K., Padvathi, A. and Thulsiraj, R.D. (2003) Sex Inequalities in Cataract Blindness, Burden and Surgical Services in South India. British Journal of Ophthalmology, 87, 847-849. http://dx.doi.org/10.1136/bjo.87.7.847

[44] Sommer, A. (2012) Under-Utilization of Eye Services. American Journal of Preventive Medicine, 43, 119-120. http://dx.doi.org/10.1016/j.amepre.2012.03.010

[45] Baker, R.S., Bazargan, M., Bazargan-Hejazi, S. and Calderón, J.L. (2005) Access to Vision Care in an Urban LowIncome Multi-Ethnic Population. Ophthalmic Epidemiology, 12, 1-12. http://dx.doi.org/10.1080/09286580590921330

[46] Tielsch, J.M., Sommer, A., Katz, J., Quigley, H. and Ezrine, S. (1991) Socio-Economic Status and Visual Impairment among Urban Americans. JAMA Ophthalmology, 109, 637-641. http://dx.doi.org/10.1001/archopht.1991.01080050051027

[47] Bourne, R.R., Dineen, B.P., Huq, D.M., Ali, S.M. and Johnson, G.J. (2004) Correction of Refractive Error in the Adult Population of Bangladesh: Meeting the Unmet Need. Investigative Ophthalmology and Visual Science, 45, 410-417. http://dx.doi.org/10.1167/iovs.03-0129

[48] Mathenge, W., Kuper, H., Polack, S., Onyango, O., Nyaga, G. and Foster, A. (2007) Rapid Assessment of Avoidable Blindness in Nakuru District, Kenya. Ophthalmology, 114, 599-605. http://dx.doi.org/10.1016/j.ophtha.2006.06.057

[49] He, M., Chan, V., Baruwa, E., Gilbert, D., Frick, K.D. and Congdon, N. (2007) Willingness to Pay for Cataract Surgery in Rural Southern China. Ophthalmology, 114, 411-416. http://dx.doi.org/10.1016/j.ophtha.2006.09.012

[50] Kessy, J.P. and Lewallen, S. (2007) Poverty as a Barrier to Accessing Cataract Surgery: A Study from Tanzania. British Journal of Ophthalmology, 91, 1114-1116. http://dx.doi.org/10.1136/bjo.2006.112474 
[51] Ashaye, A., Ajuwon, A.J. and Adeoti, C. (2006) Perception of Blindness and Blinding Eye Conditions in Rural Communities. Journal of the National Medical Association, 98, 887-893.

[52] Maher, P. (1999) A Review of “Traditional” Aboriginal Health Beliefs. Australian Journal of Rural Health, 7, $229-236$. http://dx.doi.org/10.1046/j.1440-1584.1999.00264.x

[53] Holden, B.A. (2007) Blindness and Poverty: A Tragic Combination. Clinical and Experimental Optometry, 90, 401403. http://dx.doi.org/10.1111/j.1444-0938.2007.00217.x

[54] Kasi, P.M., Gilani, A.I., Ahmad, K. and Janjua, N.Z. (2004) Blinding Trachoma: A Disease of Poverty. PLoS Medicine, 1, Article ID: e44. http://dx.doi.org/10.1371/journal.pmed.0010044

[55] Hoechsmann, A., Metcalfe, N., Kanjaloti, S., Godia, H., Mtambo, O., Chipeta, T., Barrows, J., Witte, C. and Courtright, P. (2001) Reduction of Trachoma in the Absence of Antibiotic Treatment: Evidence from a Population-Based Survey in Malawi. Ophthalmic Epidemiology, 8, 145-153. http://dx.doi.org/10.1076/opep.8.2.145.4169

[56] Frazier, M. and Kleinstein, R.N. (2009) Access and Barriers to Vision, Eye, and Health Care. Optometric Care within the Public Health Community. Old Post Publishing, Cadyville, New York.

[57] Brien Holden Vision Institute Foundation (International Centre for Eyecare Education) (2006) Situational Analysis on Refractive Error and Low Vision Services in East, Central and Southern Africa.

[58] Hou, F. and Chen, J. (2003) Neighbourhood Low Income, Income Inequality and Health in Toronto. Health Reports, 14, 21-34.

[59] Dienye, P.O., Brisibe, S.F. and Eke, R. (2011) Sources of Healthcare Financing among Surgical Patients in a Rural Niger Delta Practice in Nigeria. Rural and Remote Health, 11, 1577. http://www.rrh.org.au/publishedarticles/article_print_1577.pdf

[60] World Hunger Education Service (2011) World Hunger and Poverty Facts and Statistics. www.worldhunger.org

[61] Ryskulova, A., Turczyn, K., Makuc, D.M., Cotch, M.F., Klein, R.J. and Janiszewski, R. (2008) Self-Reported AgeRelated Eye Diseases and Visual Impairment in the United States: Results of the 2002 National Health Interview Survey. American Journal of Public Health, 98, 454-461. http://dx.doi.org/10.2105/AJPH.2006.098202

[62] Lewallen, S. (2008) Poverty and Cataract-A Deeper Look at a Complex Issue. PLoS Medicine, 5, Article ID: e245. http://dx.doi.org/10.1371/journal.pmed.0050245

[63] Baker, W. (2002) Rural Fuel Poverty Defining a Research Agenda. A Report to Eagle Charitable Trust, Centre for Sustanable Development. http://hdl.handle.net/10068/529067

[64] Melese, M., Alemayehu, W., Friedlander, E. and Courtright, P. (2004) Indirect Costs Associated with Accessing Eye Care Services as a Barrier to Service Use in Ethiopia. Tropical Medicine and International Health, 9, 426-431. http://dx.doi.org/10.1111/j.1365-3156.2004.01205.x

[65] Faal, H. and Gilbert, C. (2007) Convincing Governments to Act: Vision 2020 and the Millennium Development Goals. Community Eye Health Journal, 20, 62-64.

[66] Gersbeck, J. (2010) Eye Health and the MDGs: Progress in Asia and the Pacific. http://www.vision2020australia.org.au/uploads/resource/104/Vision2020Australia_2014-15FederalBudgetSubmission$\underline{\mathrm{rtf} . \mathrm{rtf}}$

[67] Palmer, M. (2011) Disability and Poverty: A Conceptual Review. Journal of Disability Policy Studies, 21, $210-218$. http://dx.doi.org/10.1177/1044207310389333

[68] Sen, A. (1997) From Income Inequality to Economic Inequality. Southern Economic Journal, 64, 383-401. http://dx.doi.org/10.2307/1060857

[69] (2009) The War on Poverty Campaign Report. Presentation to the Portfolio Committee on Social Development. http://www.pmg.org.za/docs/2009/091013waronpoverty-edit.pdf 
Scientific Research Publishing (SCIRP) is one of the largest Open Access journal publishers. It is currently publishing more than 200 open access, online, peer-reviewed journals covering a wide range of academic disciplines. SCIRP serves the worldwide academic communities and contributes to the progress and application of science with its publication.

Other selected journals from SCIRP are listed as below. Submit your manuscript to us via either submit@scirp.org or Online Submission Portal.
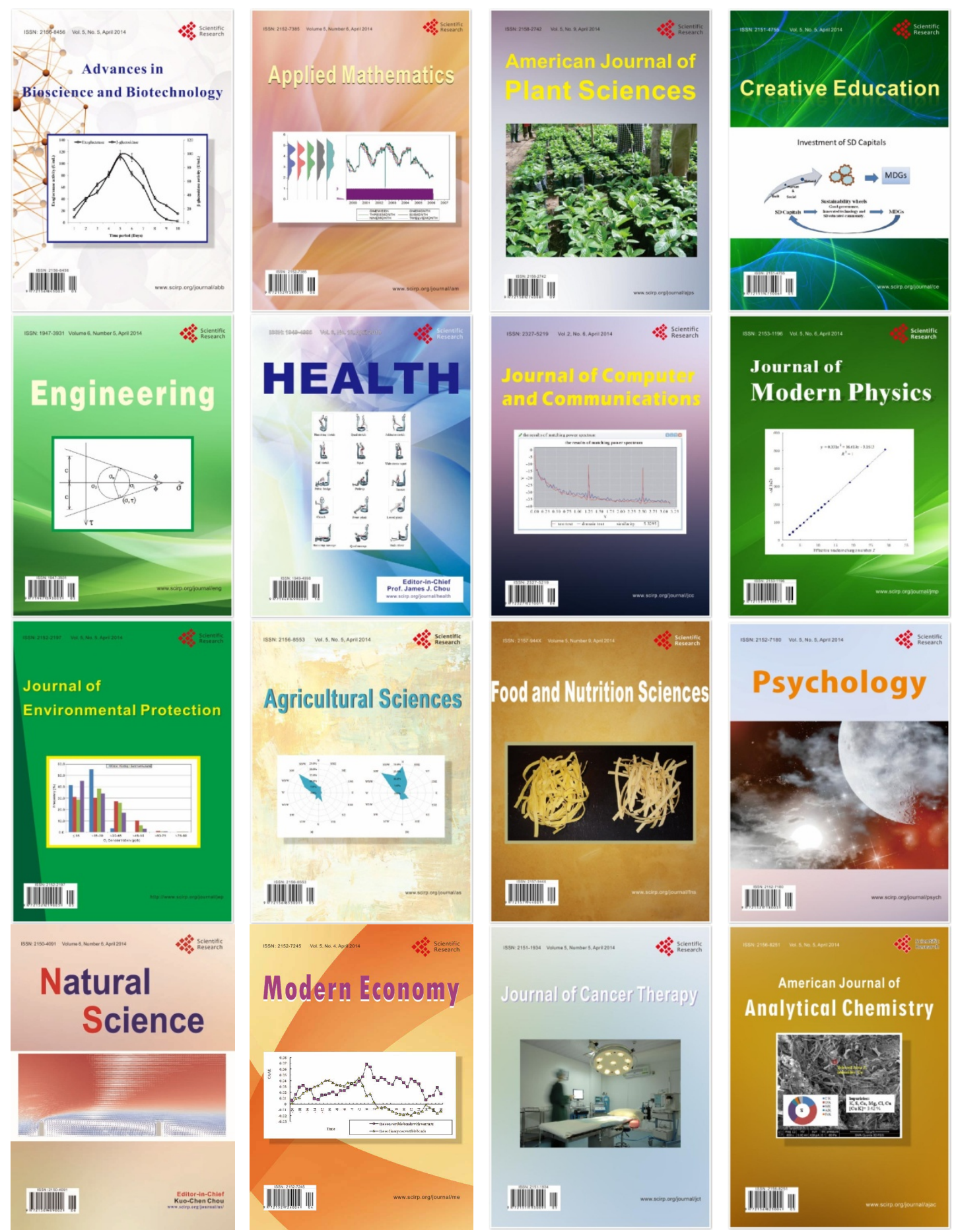